\section{Se recomienda seguir estudiando el virus de la viruela}

A principios de diciembre de 1999, en una reunión en la sede de la OMS en Ginebra, un grupo internacional de salubristas y expertos en diferentes disciplinas científicas recomendó hacer estudios adicionales sobre el virus de la viruela antes de destruir las únicas dos colecciones del virus que aún quedan en el mundo. El Comité Asesor sobre investigaciones en este campo fue creado por solicitud de la Asamblea Mundial de la Salud celebrada en mayo de 1999 y se compone de 16 miembros de 16 países ubicados en todas las regiones de la OMS. La reunión tuvo por objetivo principal determinar si hay motivos para seguir estudiando el virus de la viruela, a modo de poder fijar la fecha en que se deben destruir los reservorios víricos restantes, actualmente postergada por la Asamblea para fines de 2002 con la posibilidad de revisiones anuales. Durante la reunión se destacaron ciertas actividades de investigación que podrían beneficiar a la humanidad: secuenciar porciones más extensas del ADN vírico; desarrollar pruebas para la detección del virus en seres humanos, y elaborar medicamentos para tratar la infección humana, en la eventualidad de una reaparición.

Los dos últimos reservorios del virus de la viruela, que fueron creados en los años ochenta a partir de aportaciones de laboratorios en varios países, se encuentran en el Centro Estatal de Investigaciones en Virología y Biotecnología de Koltsovo, Rusia, y en los Centros para el Control y la Prevención de Enfermedades, en Atlanta, Georgia, Estados Unidos, ambos de los cuales son Centros Colaboradores de la OMS.

La OMS autorizará y revisará todas las investigaciones sobre el virus de la viruela de ahora en adelante. El financiamiento de las investigaciones correrá por cuenta de los Estados Miembros o de otros organismos nacionales o internacionales que deseen subsidiar estas actividades. De esta forma se garantizará que los fondos destinados por la OMS a los problemas de salud de mayor importancia, como el paludismo, la tuberculosis y el sida, no sean dirigidos al estudio de la viruela.

Con el tiempo, el Comité Asesor creará un mecanismo para notificar los resultados de las investigaciones y establecerá un calendario de inspección destinado a confirmar la contención estricta de los reservorios víricos existentes y a garantizar la inocuidad y seguridad del entorno en que se llevarán a cabo las investigaciones.

La erradicación mundial del virus de la viruela, declarada en mayo de 1980, suele considerarse hasta la fecha el logro más espectacular en la historia de la OMS, que coordinó las iniciativas internacionales de erradicación. (Organización Mundial de la Salud. Future research on smallpox virus recommended. Comunicado de prensa $\mathrm{WHO} / 77$, 10 de diciembre de 1999.)

\section{La erradicación de Helicobacter pylori y su asociación con la anemia ferropénica}

La atención estándar de pacientes adultos con anemia ferropénica comprende una evaluación para descartar anomalías de las vías digestivas, aunque en alrededor de $30 \%$ de los casos este tipo de evaluación no conduce a un diagnóstico. Algunas investigaciones recientes apuntan a una relación entre la anemia ferropénica y la infección por la bacteria Helicobacter pylori, agente causal de úlceras pépticas y cánceres gástricos que pueden sangrar de manera oculta o visible y con el tiempo producir una anemia ferropénica. La mayoría de las personas infectadas por $H$. pylori tienen, sin embargo, solamente una gastritis crónica que no suele asociarse con hemorragia gastrointestinal o con otra enfermedad en particular. Se ha postulado que en estos casos la anemia ferropénica podría deberse a una interferencia con la captación del hierro o a un aumento de las necesidades de hierro del organismo por acción de la bacteria. Respalda esta teoría la desaparición de la anemia después de haberse erradicado H. pylori en niños y en un adulto joven en fecha reciente.

Con el fin de observar el efecto de la erradicación de H. pylori en pacientes anémicos, un grupo de investigadores estudió entre septiembre de 1994 y diciembre de 1997 una muestra de 30 pacientes mayores de 20 años con anemia moderada o grave que habían sido remitidos a un servicio de gastroenterología. Todos los pacientes tenían largos antecedentes de anemia ferropénica (hemoglobina $<14 \mathrm{~g} / \mathrm{L}$ en hombres y $<12 \mathrm{~g} / \mathrm{L}$ en mujeres) y fueron sometidos a recuento de hemoglobina, determinación de las concentraciones de ferritina y gastroscopia con biopsia del antro pilórico o del cuerpo 
estomacal. La detección de H. pylori se hizo por examen histológico, prueba rápida de ureasa, o ambas. Los pacientes habían tenido una respuesta subóptima al consumo oral de suplementos de hierro y necesitaban su administración continua o intermitente para prevenir un descenso de la hemoglobina. Todos los pacientes fueron tratados 2 semanas con $40 \mathrm{mg}$ de omeprazol por las mañanas y $1 \mathrm{~g}$ diario de amoxicilina, y durante la primera semana recibieron $250 \mathrm{mg}$ de metronidazol tres veces al día después de las comidas. A todos se les suspendió la administración de un suplemento de hierro y se les pidió que se abstuvieran de reiniciar la suplementación por espacio de un año. Cada paciente acudió a consultas de seguimiento a los 3, 6 y 12 meses de su ingreso en el estudio.

El único hallazgo en los 30 pacientes fue una gastritis asociada con la infección por H. pylori. No se obsrvaron huellas de erosión o ulceración de la mucosa gástrica. Al cabo de los primeros 3 meses ninguno de los pacientes manifestaba síntomas de anemia. A los 6 meses de ingresar en el estudio, 28 pacientes fueron sometidos a endoscopia (dos declinaron la prueba porque se sentían bien) y 25 ya no estaban infectados por $H$. pylori. De estos últimos pacientes, 18 ya no tenían anemia pese a no haber ingerido suplementos de hierro. A los 12 meses, 91,7\% de los pacientes se habían recuperado de la anemia por completo. En resumen, estos datos revelan que la cura de la infección por $H$. pylori determina la desaparición de la dependencia de hierro y de la anemia, con una restauración progresiva de las concentraciones de ferritina durante los 12 a 24 meses subsiguientes. (Annibale B, Marignani M, Monarca B, Antonelli G, Marcheggiano A, Martino $\mathrm{G}$, et al. Reversal of iron deficiency anemia after $\mathrm{He}$ licobacter pylori eradication in patients with asymptomatic gastritis. Ann Intern Med 1999;131:668-672.)

\section{Tratamiento promisorio contra la diarrea producida por el cólera}

Se sabe que los ácidos grasos de cadena corta, que se producen en el colon a partir de carbohidratos no absorbidos, aumentan la reabsorción del sodio. Un grupo de investigadores se propuso aprovechar esta propiedad de los ácidos grasos para mejorar el cuadro diarreico asociado con el cólera, ya que la terapia de rehidratación oral a base de glucosa corrige la deshidratación pero no la diarrea. Con este fin administraron a 48 pacientes adolescentes y adultos una de las siguientes fórmulas orales: terapia de rehidratación estándar (16 pacientes); terapia de rehidratación estándar más $50 \mathrm{~g}$ de harina de arroz por litro de solución (16 pacientes); o terapia de rehidratación estándar y $50 \mathrm{~g}$ de mai- cena con alto contenido de amilosa (16 pacientes), producto resistente a la acción de la amilasa, por litro de solución. Las variables clínicas de interés fueron el peso del bolo fecal (para cada período de 12 horas durante las primeras 48 horas después del inicio del tratamiento) y el tiempo transcurrido hasta la primera evacuación sólida.

Los pesos promedios ( \pm desviación estándar, DE) correspondientes a los períodos de 12 a 24, 24 a 36 y 36 a 48 horas después de iniciado el tratamiento, fueron más bajos en el grupo que recibió el almidón resistente (2 $206 \pm 1158 \mathrm{~g}, 1810 \pm 1018 \mathrm{~g}$ y $985 \pm 668 \mathrm{~g})$ que en el grupo que recibió el tratamiento estándar (3 $251 \pm 766$ g, $2621 \pm 1149$ g y $2498 \pm 1080 \mathrm{~g} ; P=0,01, P=0,04$ y $P=0,001$, respectivamente), siendo estadísticamente significativa la diferencia. También se observó una diferencia significativa entre el peso fecal del grupo tratado con almidón resistente y el del grupo que fue tratado con harina de arroz, pero solamente en el período de 36 a 48 horas después de empezar el tratamiento $(985 \pm 668 \mathrm{~g}$ frente a $1790 \pm 866 \mathrm{~g} ; P=0,01)$. La duración media de la diarrea fue mucho más corta en el grupo que recibió la terapia a base de maicena resistente $(56,7 \pm 18,6$ horas) que en el que recibió únicamente el tratamiento estándar $(90,9 \pm 29,8$ horas; $P=0,001)$ o este último más harina de arroz $(70,8 \pm$ $20,2$ horas; $P=0,05)$. La excreción fecal de almidones fue mayor en el grupo tratado con la maicena resistente $(32,6 \pm 30,4)$ que en el que recibió el tratamiento estándar $(11,7 \pm 4,1 \mathrm{~g} ; P=0,002)$ o el que también recibió harina de arroz $(15,1 \pm 8,4 ; P=0,01)$.

A partir de estos datos los autores concluyen que la adición de un almidón a la solución de rehidratación oral reduce la pérdida de líquido por las heces y acorta la diarrea en pacientes adolescentes y adultos con cólera. (Ramakrishna BS, Venkataraman S, Srinivasan P, Dash P, Young GP, Binder HJ. Amylase-resistant starch plus oral rehydration solution for cholera. New Engl J Med 2000;342: 308-313.)

\section{El riesgo de transmisión vertical del VIH es mayor en el período neonatal temprano}

El riesgo que corre un recién nacido de ser infectado por el virus de la inmunodeficiencia humana (VIH) al ingerir la leche de una madre infectada es mayor en los primeros meses de la vida, según revelan los resultados de un estudio nuevo que se ha llevado a cabo en Malawi. La falta de experiencia de la madre con la lactancia materna también puede en estos casos incrementar el peligro de transmisión por la leche.

Los investigadores, que son expertos de los Institutos Nacionales de Salud en Bethesda, Mary- 
land, de la Universidad Johns Hopkins en Baltimore, Maryland, y de la Facultad de Medicina de Blantyre, Malawi, consideran que sus resultados tienen gran importancia en tanto es muy poco lo que hasta ahora se ha sabido acerca del momento en que se produce la infección en neonatos de madres infectadas. Sobre la base de estos datos nuevos las madres con infección por VIH podrán tomar mejores decisiones en relación con la lactancia materna.

La lactancia al pecho es la forma de alimentación recomendada para neonatos en países en desarrollo, donde los sustitutos de la leche materna suelen ser escasos, peligrosos o rechazados debido a factores culturales. En los Estados Unidos de América, donde sí hay acceso a otros productos seguros y de buena calidad, no se recomienda a las mujeres infectadas por el VIH que den de mamar a sus hijos. Para determinar el momento en que se produce la infección vertical y los factores de riesgo que se asocian con la infección, los autores del estudio aquí descrito efectuaron pruebas para la detección de VIH en neonatos durante las visitas del período posneonatal en un hospital urbano de Malawi. Solamente los niños que tuvieron resultados negativos en su primera prueba, que tuvo lugar a las 6 semanas de nacidos, fueron incluidos en el estudio, ya que la positividad en las primeras semanas de vida podría ser consecuencia de una infección adquirida durante el embarazo o el parto, y no solamente como resultado de la lactancia.

Las pruebas detectoras de VIH que se administraron en los dos años posteriores revelaron que 47 de los 672 niños estudiados adquirieron la infección por la leche materna. Casi la mitad (21) de las infecciones ocurrieron en los primeros 5 meses de la vida de los neonatos y otros 15 niños se infectaron entre los 6 y 11 meses posteriores al nacimiento. Siete más adquirieron la infección a los 12 a 17 meses de nacidos. Solamente cuatro infecciones se produjeron entre 18 y 23 meses después del nacimiento. Ninguno de los neonatos adquirió la infección por VIH después del destete.

Los investigadores llegan a la conclusión de que las madres con relativamente poca experiencia en materia de lactancia son más propensas a tener mastitis, inflamación del tejido mamario que facilita el paso del virus a la leche. En otro estudio reciente, según explican estos investigadores, se encontró una mayor concentración de VIH en la leche de madres con mastitis subclínica y una mayor tasa de transmisión en los hijos lactantes de estas madres.

Como medida protectora contra la transmisión de VIH por la leche materna se ha propuesto suspender la lactancia más temprano. Aunque en este estudio la medida hubiera prevenido la mitad de las infecciones neonatales observadas, cabe recordar que el destete temprano expone al niño al riesgo de morir de enfermedades respiratorias y diarreicas por falta de los anticuerpos que la madre transmite a sus hijos durante la lactancia. Ello significa que en países en desarrollo el riesgo de infección y los beneficios de la leche materna deben sopesarse cuidadosamente a la luz de estos resultados antes de decidir la conducta que debe seguirse en casos individuales. (Miotti PG, Taha TET, Kumwenda NI, Broadhead R, Mtimavalye LA, Van der Hoeven L, et al. HIV transmission through breastfeeding: a study in Malawi. JAMA 1999;282(8)781-783.)

\section{La epidemia de sida sigue teniendo proporciones catastróficas}

Desde que comenzó en los años ochenta la epidemia del síndrome de la inmunodeficiencia humana (sida), 50 millones de personas en el mundo entero han adquirido la infección por el virus de la inmunodeficiencia humana (VIH) y 16 millones han perdido la vida como consecuencia de esta infección. Los otros 33 millones aún permanecen vivos con la infección, según revelan las estadísticas más recientes de la OMS y del Programa Conjunto de las Naciones Unidas sobre el VIH/SIDA (UNAIDS). El informe correspondiente, titulado AIDS Epidemic Update - December 1999, indica que en 1999 el sida cobró 2,6 millones de vidas, más que en cualquier otro año, y las infecciones nuevas ascendieron a 5,6 millones en personas de todas las edades. Es evidente que la infección por VIH sigue propagándose a un ritmo similar al de años anteriores.

Cuando una epidemia tiene la magnitud de la del sida, cualquier caso nuevo de infección tiene repercusiones patentes por su efecto en la familia, la comunidad, los negocios y la economía. En muchos países del mundo, el sida representa el mayor obstáculo al progreso y desarrollo nacionales. Es imprescindible que los servicios de salud puedan hacer frente a las necesidades de las personas positivas a VIH que se enferman de sida, lo cual encierra la necesidad de desestigmatizar a las personas infectadas, facilitar su acceso a los servicios de salud e idear tratamientos de bajo costo para las infecciones oportunistas. La OMS, en colaboración con los ministerios de salud de muchos países, lucha por poner al alcance de personas infectadas por VIH los servicios y recursos que necesitarán cuando la infección progrese al sida. Es de esperar que si va en aumento el número de personas infectadas, como demuestran las últimas estadísticas, en pocos años se observe también un aumento del número de personas que contraen el sida y que mueren de la enfermedad.

En el África subsahariana, que en este momento representa el epicentro de la epidema mun- 
dial, las mujeres tienen una tasa de infección por VIH más alta que los hombres, siendo de 1,1:1 la razón mujeres:hombres. Estudios en varios países africanos también revelan que las jóvenes de 15 a 19 años corren un riesgo de infección de cinco a seis veces mayor que el de varones de la misma edad. Contribuyen a este fenómeno la facilidad de la transmisión del hombre a la mujer y la frecuencia de las relaciones sexuales con hombres mayores que están infectados. Según datos del Programa de las Naciones Unidas para el Desarrollo, varias naciones africanas sufrieron reveses en sus índices de desarrollo. Casi invariablemente, esto se atribuyó a una reducción de la esperanza de vida como consecuencia del sida. En la antigua Unión Soviética, el mayor uso de drogas inyectables ha provocado el ascenso más acelerado de la infección por VIH que se ha visto en el mundo hasta ahora.

Pero pese a todos estos datos alarmantes, hay motivo para sentir cierto optimismo, aun en las zonas del mundo que se ven más azotadas por la epidemia. En ciertas partes del mundo se ha logrado contener el número de infecciones nuevas y mejorar la calidad de la vida de las personas que ya tienen la infección. Tailandia y las Filipinas tienen programas preventivos cuya efiacia ha sido demostrada y algunos países de América Latina se han sumado a aquellos que desde hace algún tiempo proporcionan medicamentos antirretrovíricos gratuitos a personas infectadas por VIH.

$\mathrm{Al}$ emitir su informe, el UNAIDS pidó encarecidamente a los países industrializados que refuercen sus programas para la prevención de la infección por VIH, dado que la epidemia no se ha mitigado en ningún país del mundo. Cabe recordar que, si bien los antirretrovíricos representan un rayo de esperanza para quienes tienen la fortuna de poder adquirirlos, no son una panacea y no son fáciles de conseguir en muchas partes del mundo. La clave de la lucha contra el sida sigue radicando indiscutiblemente en la prevención de infecciones nuevas. (Organización Mundial de la Salud. AIDS not losing momentum-HIV has infected 50 million, killed 16 million, since epidemic began. Comunicado de prensa $\mathrm{WHO} / 66,23$ de noviembre de 1999).

\section{Estrategia integrada para la vigilancia de enfermedades transmisibles}

El control de las enfermedades transmisibles depende de la integridad de los sistemas de respuesta y estos a su vez se apoyan en medidas de vigilancia epidemiológica eficaces. Es preciso contar con un sistema de vigilancia funcional para obtener información que sirva de base a la determinación de las enfermedades transmisibles de prioridad. Asimismo, en cualquier país dicho sistema es un instrumento indispensable para la toma de decisiones sanitarias. Los datos generados por los sistemas de vigilancia proporcionan información que puede aplicarse a la hora de sentar prioridades, diseñar políticas, movilizar y adjudicar recursos y pronosticar brotes o epidemias. Los sistemas de vigilancia también pueden ser útiles para monitorear, evaluar y mejorar los programas de prevención y control de enfermedades.

En la actualidad, muchos países llevan a cabo actividades de vigilancia en torno a las enfermedades transmisibles con el fin de monitorear las que se asocian con una elevada carga de morbilidad, detectar brotes de enfermedades tendientes a convertirse en epidemias y seguir los adelantos hacia las metas de control o erradicación establecidas en el ámbito nacional o internacional. No obstante, las actividades de vigilancia se han desarrollado sin uniformidad, según el ritmo de las amenazas planteadas por enfermedades específicas y las respuestas dadas por los países individualmente. Por añadidura, los sistemas de vigilancia están desactualizados, con el resultado de que se recogen datos en cantidades abrumadoras en el nivel central sin que se efectúe con ellos ningún tipo de análisis de utilidad para la toma de decisiones. El modelo de vigilancia vertical que impera en la mayoría de los países lleva a problemas de ineficiencia debidos al uso de diferentes metodologías, terminologías y formularios. A menudo se mantienen metas anticuadas sin la debida atención a problemas de actualidad, tales como la vigilancia de la resistencia a los antimicrobianos.

Frente a la situación descrita se impone la necesidad de adoptar un nuevo paradigma en forma de un sistema integrado, equivalente a la suma de todas las actividades de vigilancia que juntas configuran el sistema de vigilancia nacional. Según este enfoque, todas las actividades de vigilancia constituyen un servicio público común que ejerce distintas funciones mediante el uso de estructuras, procesos y recursos humanos similares. Las actividades que gozan de un buen desarrollo en determinada área pueden servir de estímulo y refuerzo a otras actividades de vigilancia, produciéndose así un sinergismo y un uso compartido de recursos. El punto de partida para la instauración de este nuevo paradigma debe ser un plan para la vigilancia reforzada de enfermedades prioritarias, con el debido compromiso político y apoyo financiero.

No cabe duda que la coordinación de las actividades de vigilancia y respuesta redunda en una reducción de costos y mayor eficiencia en el nivel nacional. Esta coordinación puede lograrse por medio de cuatro elementos: 1) el adiestramiento del personal de salud en epidemiología; 2) el fortaleci- 
miento de los laboratorios; 3) el mejoramiento de la infrasteructura de comunicaciones, y 4) una mayor atención al sector de la salud, en sus componentes público y privado, que representa la primera línea de las actividades de vigilancia.

Las autoridades de salud pública deben prestar mayor atención a fuentes de información ajenas al componente gubernamental o público del sector de la salud, entre ellas las que proceden de organizaciones no gubernamentales y los medios de comunicación. La habilidad de dichas autoridades de responder con rapidez a información sobre brotes de enfermedad proveniente de cualquier fuente es esencial si se ha de mantener un sistema de vigilancia eficiente y fiable. Para alcanzar esta credibilidad, el primer paso debe consistir en el desarollo de un sistema integrado para responder a enfermedades múltiples; el segundo debe ser el fortalecimiento de las actividades de vigilancia ya existentes.

Por último, debe hacerse un esfuerzo especial por desarrollar indicadores de calidad para evaluar el sistema, teniendo en cuenta no solo la necesidad de que los indicadores sean genéricos y universales, sino también la diversidad de los sistemas de vigilancia y los contextos específicos en que operan. (Organización Mundial de la Salud. An integrated approach to communicable disease surveillance. Wkly Epidemiol Rec 2000;75:1-7.)

\section{Los últimos conocimientos sobre la enfermedad de Alzheimer}

En el proceso de envejecimiento normal, no se pierden enormes cantidades de neuronas cerebrales. En cambio, esta pérdida sí ocurre en pacientes de enfermedad de Alzheimer debido a la alteración de tres procesos clave: la comunicación intercelular, el metabolismo celular y los mecanismos de reparación. A la larga estas alteraciones llevan a las neuronas a dejar de funcionar, a perder su comunicación con otras células y a fenecer. El proceso de destrucción suele iniciarse en aquellas partes del cerebro que controlan la memoria, especialmente el hipocampo. Al principio esto conduce a una pérdida de la memoria reciente y a una disminución de la capacidad para llevar a cabo algunas actividades cotidianas. Más tarde hay una degeneración de la corteza cerebral, particularmente de las zonas responsables del lenguaje y de la capacidad de raciocinio. Se producen alteraciones del habla y del juicio, en muchos casos acompañadas de cambios de personalidad que llevan a episodios de agitación y crisis emocionales, hasta que el paciente acaba postrado, incontinente, completamente desvalido y ajeno al mundo que lo rodea.

El cerebro afectado por la enfermedad de Alzheimer presenta dos anomalías morfológicas: placas amiloides y ovillos neurofibrilares. En época reciente los científicos han logrado descifrar la composición de estas lesiones y las etapas de su formación, aunque aún desconocen si dan origen a los síntomas o si son más bien un resultado secundario de la enfermedad. Pero aún quedan por resolver varios interrogantes, quizá los que plantean mayor dificultad: ¿Qué desencadena el proceso degenerativo en primer lugar y qué factores contribuyen a su desarrollo? ¿Por qué aumenta con la edad su prevalencia? Hay enfermedades, como la tuberculosis, cuya causa es fácil de identificar. Pero este no es el caso de la enfermedad de Alzheimer. Al igual que la artritis y la diabetes mellitus, esta afección obedece a una confluencia de factores genéticos y ambientales y a una serie de fenómenos que se producen en cascada en el cerebro a lo largo de un período prolongado.

Hay dos tipos de enfermedad de Alzheimer: la familiar, que muestra determinado patrón hereditario, y la esporádica, que no muestra ningún patrón de este tipo. Además, hay una variedad relativamente rara que se presenta a edad temprana (antes de los 65 años) y que progresa con rapidez, y otra más común y lenta que aparece en edad avanzada. De la forma familiar, alrededor de $50 \%$ se atribuye a la mutación de tres genes situados en los cromosomas 21, 14 y 1. Basta con la mutación de uno de estos genes en un solo cromosoma para que se presente la enfermedad. Todavía no hay pruebas, sin embargo, de que cualquiera de estas mutaciones ejerza un papel importante en la aparición de su forma esporádica. Actualmente los científicos se concentran en tratar de descifrar de qué manera las mutaciones genéticas desencadenan la forma familiar de la enfermedad de Alzheimer y de momento existen numerosas teorías al respecto. De gran interés es la posibilidad de que haya diferencias étnicas y raciales en el riesgo de sufrir la enfermedad, habiéndose observado una mayor propensión en personas cuacásicas que en las hispanoamericanas o de origen africano.

También se han investigado los factores no genéticos que contribuyen al desencadenamiento de la enfermedad. Se cree, entre otras cosas, que con el envejecimiento las neuronas están sujetas al efecto nocivo de la acumulación prolongada de radicales libres, que son productos del metabolismo celular, dentro de las neuronas. Los radicales libres en cantidades excesivas pueden lesionar las células porque son moléculas muy reactivas con la capacidad para modificar otras moléculas cercanas, tales como las de la membrana celular o el ADN, proceso que a su vez estimula la creación de más radicales libres. Ciertas características del cerebro, entre ellas su metabolismo acelerado y la larga vida propia de las neuronas, lo tornan especialmente susceptible al efecto de los procesos de oxidación. 
Resulta cada vez más claro que la enfermedad de Alzheimer guarda asociación con otras enfermedades cerebrales, como las que son producidas por priones (proteínas infecciosas recién identificadas), la enfermedad de Parkinson, la corea de Huntington y la demencia frontotemporal. Puede ser que el estudio de la formación de fibrillas de amiloide, propia de las enfermedades causadas por priones, arroje luz sobre la enfermedad de Alzheimer, y que también suceda algo similar cuando se estudien más a fondo las alteraciones genéticas propias de la enfermedad de Parkinson.

Existen actualmente mejores técnicas de diagnóstico que pueden aplicarse en vida y que llevan a la identificación de la enfermedad de Alzheimer en 90\% de los casos. Se están elaborando pruebas de función mental capaces de distinguir entre las personas con signos muy tempranos de la enfermedad y las que tienen una pérdida normal de la memoria en función de su edad. También se están explorando maneras de medir en el líquido cefalorraquídeo las concentraciones de ciertas sustancias amiloides y proteínicas cuya presencia pueda servir para diagnosticar la enfermedad. Algunos investigadores han empleado la tomografía por emisión de positrones (positron emission tomography, o PET) para detectar cambios en el metabolismo de la glucosa en las partes del cerebro que se ven afectadas. Se presenta también la posibilidad muy halagadora de usar la resonancia magnética (magnetic resonance imaging, MRI) para medir el tamaño de varias estructuras cerebrales, entre ellas el hipocampo, que se empiezan a atrofiar en etapa temprana de la en- fermedad. Incluso es posible refinar el uso de esta técnica hasta poder identificar a las personas cuya pérdida de la memoria se debe a la enfermedad de Alzheimer en fase temprana y a las que sufrirán la enfermedad en etapa posterior.

En cuanto al tratamiento de la enfermedad de Alzheimer, los científicos esperan poder descubrir medicamentos que contrarresten los procesos degenerativos fundamentales. En este momento la Food and Drug Administration de los Estados Unidos ha autorizado dos fármacos que inhiben la acetilcolinesterasa, sustancia que degrada la acetilcolina, a su vez necesaria para la integridad de las funciones cognoscitivas. Uno de ellos es el donezepil, que se usa en casos incipientes, y el otro, la tacrina. El segundo tiene más efectos secundarios que el primero, ayuda solamente a una fracción de los pacientes y por un período máximo de 2 años, y no revierte los síntomas de la enfermedad. Algunos estudios epidemiológicos apuntan hacia la posibilidad de que la terapia estrogénica de reemplazo y el uso regular de algunos antiinflamatorios no esteroides se asocien con un menor riesgo de enfermar. Pero los científicos advierten que estos medicamentos no deben usarse solamente con la intención de conservar intactas las funciones cognoscitivas o de protegerse contra la enfermedad de Alzheimer. Primero es necesario efectuar numerosos ensayos clínicos para confirmar la eficacia y la inocuidad de estos enfoques terapéuticos. (National Institute on Aging. Alzheimer's disease: a puzzle being solved. En: Progress Report on Alzheimer's Disease. Silver Spring, Maryland: NIA; 1999.) 